\title{
Motor Profile of Students With Dyslexia
}

\author{
Paola Matiko Martins \\ Okuda \\ Universidade Estadual \\ Paulista_FFC/UNESP, \\ Marília-São Paulo, Brazil
}

\author{
Fabiana Garcia Ramos, \\ Lara Cristina Antunes \\ dos Santos, Niura \\ Aparecida de Moura \\ Ribeiro Padula \\ Universidade Estadual \\ Paulista-FM/UNESP, \\ Botucatu-São Paulo, Brazil
}

\author{
Amanda Kirby \\ The Dyscovery Centre, \\ University of South Wales, \\ Newport, UK
}

Simone Aparecida

Capellini

Universidade Estadual

Paulista_FFC/UNESP,

Marília-São Paulo, Brazil

In the presence of developmental dyslexia, there is high probability of motor difficulties being present as well purposes: The purposes of this study were to characterize and compare the motor performance of students with dyslexia with students with good academic performance and to identify the presence of the DCD (developmental coordination disorder) co-occurring with developmental dyslexia. A total of 79 students participated in the research, both genders, from 8 to 11 years old, from 3rd to 5th grades, and were divided into Group I: 19 students with developmental dyslexia and Group II: 60 students with good academic performance. All the students were assessed using “The Bruininks-Oseretsky Test of Motor Proficiency” (second edition), to measure the motor skills and the pattern and differences between groups. The results of this study showed that the motor performance of Group II students was superior to the performance of students of Group I in almost all motor areas assessed but both groups performed less well than they should have for their chronological age. The results of this study indicate that occupational therapists, speech therapists and educators need to be aware of the presence of motor impairments and the need for early intervention in both the academic and clinical environments, in order to ensure that early identification and diagnosis of possible co-occurrences, such as DCD, and the impact on learning to guarantee more appropriate clinical and educational assistance for this population. This may also indicate that increased exposure to movement may be important to limit some of the secondary health consequences in children in Brazil.

Keywords: developmental dyslexia, developmental coordination disorder, assessment, motor profile

Paola Matiko Martins Okuda, Master, Occupational Therapist, Department of Speech Language Pathology and Hearing, Faculty of Philosophy and Sciences, Universidade Estadual Paulista-FFC/UNESP.

Fabiana Garcia Ramos, child neurologist, Department of Neurology and Psychiatry, Faculty of Medicine, Universidade Estadual Paulista-FM/UNESP.

Lara Cristina Antunes dos Santos, Master, child neurologist, Department of Neurology and Psychiatry, Faculty of Medicine, Universidade Estadual Paulista-FM/UNESP.

Niura Aparecida de Moura Ribeiro Padula, professor, child neurologist, Department of Neurology and Psychiatry, Faculty of Medicine, Universidade Estadual Paulista-FM/UNESP.

Amanda Kirby, professor, The Dyscovery Centre, University of South Wales.

Simone Aparecida Capellini, full professor, Department of Speech Language Pathology and Hearing, Faculty of Philosophy and Sciences, Universidade Estadual Paulista-FFC/UNESP. 


\section{Introduction}

Developmental dyslexia is a disability of neurobiological origin, defined by the DSM- V (diagnostic and statistical manual of mental disorders) (APA (American Psychiatric Association), 2013) as "a specific learning disorder or a decoding difficulty in reading", that refers to children who have difficulty in mastering the relationships between the spelling patterns of words and their pronunciations. These children typically read aloud inaccurately and slowly, and experience additional problems with spelling.

It is characterized by difficulty for the correct reading fluency and by difficulty in decoding and spelling skills, beyond the presence of cognitive deficits and deficits in academic performance in other areas, such as: attention, math and/or written expression, which cause decline in the academic performance (Capellini, 2009; Capellini, Germano, \& Padula, 2010).

For this reason, most of the studies with students with dyslexia have been mainly focused on describing cognitive-linguistic behaviors related to reading and writing, as well as their influence on academic performance. However, studies indicate the presence of alterations in motor skills of this population (Kirby, 2011; Okuda, Lourencetti, Santos, Padula, \& Capellini, 2011; Siqueira \& Gurgel-Giannetti, 2011; Nicolson \& Fawcett, 2011).

Studies have indicated that in the presence of developmental dyslexia, there is a higher probability of difficulties with co-ordination affecting many aspects of life. These include challenges with both gross motor skills along with fine motor skills, impairing dexterity, speed of object manipulation, precision of movement, hand posture and writing skills, and impacting on functional tasks, such as: buttoning, using scissors, handling coins, pencils and writing (Summer, Larkin, \& Dewey, 2008; Martin, Piek, Baynam, Levy, \& Hay, 2010). The literature (Rochelle \& Talcott, 2006; Corriveau \& Goswami, 2009; Valdois, 2010; Stoodley \& Stein, 2011) also describes problems in balance, motor control, rhythm and speed, and automatization of the movement.

The relationship between dyslexia and alterations in motor coordination have been described as important relationships to be established at the time of assessment and diagnosis (Nicolson \& Fawcett, 2011; Pieters et al., 2012).

The motor difficulties often coexist (or co-occur) with dyslexia; in this case, specifically DCD (developmental coordination disorder). The literature indicates that the coexistence of DCD and dyslexia can occur from 35 to 50\% of the cases (Kirby, Sugden, Beveridge, L. Eduards, \& R. Edwards, 2008; Pieters et al., 2011; Gooch, Hulme, Nash, \& Snowling, 2013).

DCD, according to DSM-V (APA, 2013) is classified as a motor disorder, condition characterized by motor performance that is substantially below expected levels, given the person's chronologic age and previous opportunities for skill acquisition. The poor motor performance may manifest as coordination problems, poor balance, clumsiness, dropping or bumping into things; marked delays in achieving developmental motor milestones (e.g., walking, crawling, and sitting) or in the acquisition of basic motor skills (e.g., catching, throwing, kicking, running, jumping, hopping, cutting, coloring, printing, and writing). This disturbance, without accommodations, significantly interferes with activities of daily living or academic achievement. Overall, DCD affects around 5\% to $6 \%$ of school-age children; at least $2 \%$ severely affected, in the general population, and is well documented to remain in adulthood for the majority to some extent (Lingam, Hunt, Golding, Jongmans, \& Emond, 2009; Tsiotra, Nevill, Lane, \& Koutedakis, 2009; Gabbard \& Caçola, 2010; Kirby, 2011). 
Studies based on the etiology of developmental dyslexia and DCD indicate that the combined presence of both is common. This has been suggested that this may be related to shared genetics and also that in both cases problems are identified in cortical areas responsible for motor processing (motor planning and sequencing and preparation of movement) and cognitive aspects, such as attention (Cruddace \& Riddell, 2006; Gabbard \& Caçola, 2010; Zwicker, Missiuna, Harris, \& Boyd, 2011; Martin, Piek, Baynam, Levy, \& Hay, 2010; Capellini, Germano, \& Padula, 2010; Simos et al., 2011; Hedenius et al., 2013).

Given the above, the purposes of this study were to characterize and compare the motor performance of students with dyslexia in relation to students with good academic performance and identify the presence of DCD and amount of co-occurrence with developmental dyslexia.

\section{Materials and Methods}

\section{Participants}

A total of 79 students participated in these research, both genders, from 8 to 11 years old, from 3rd to 5th grades, of public municipal schools, and were divided into two groups:

GI (Group I): This was composed of 19 students with an interdisciplinary diagnoses of developmental dyslexia, all attending the Supervised Internship in Speech Therapy: Reading and writing disorder carried out at the CEHS (Center of Education and Health Studies) - FFC/UNESP_Marília, comprising 15 (79\%) males and 4 (21\%) females, 3 (16\%) enrolled in the 3rd grade, 10 (53\%) enrolled in the 4th grade and 6 (31\%) enrolled in the 5th grade.

The developmental dyslexia diagnoses of these students were conducted by an interdisciplinary team from the CEHS (Center of Education and Health Studies)—FFC/UNESP_Marília and from the Ambulatory of Child Neurology Learning, from Hospital das Clínicas of Faculty of Medicine of Botucatu—UNESP, including phonoaudiological, neurological, educational, occupational therapy, and neuropsychological assessments.

GII (Group II): This was composed of 60 students with good academic performance of public municipal schools, matched according to gender and age with the GI. This matching (1 to 3), i.e., for each scholar with interdisciplinary diagnosis of developmental dyslexia, three students with good academic performance, were selected, therefore, 48 (80\%) males and 12 (20\%) females, 18 (30\%) enrolled in the 3rd grade, 30 (50\%) enrolled in the 4th grade and 12 (20\%) enrolled in the 5th grade.

Students were selected by school teachers and by considering information obtained from the school records and the student performance report of the first quarter, for Portuguese tests.

\section{Procedure}

As a resolution from the National Health Council 196/96, prior to the beginning of the assessments, parents or guardians of the selected participants signed an Informed Consent Form authorizing the study. After signing the consent form, the students were assessed individually, by the researchers in charge of this study, which was approved by the Research Ethics Committee of Faculty of Philosophy and Sciences-REC/FFC/UNESP under protocol number 2004/2009.

\section{Motor Skills Measure}

BOT-2 (The Bruininks-Oseretsky Test of Motor Proficiency (second edition)), is an internationally accepted test and provides an indication of gross and fine motor functioning for individuals from 4 to 21 years (R. H. Bruininks \& B. D. Bruininks, 2005). The procedure is composed by four motor areas and a TMC (total 
motor composite). Each motor area includes two subtests and the total motor composite comprises the sum of all subtests. Thus, the structure of the test is as follows:

(1) FMC (fine manual control): FMP (fine motor precision) and FMI (fine motor integration);

(2) MC (manual coordination): MD (manual dexterity) and UC (upper-limb coordination);

(3) BC (body coordination): BC (bilateral coordination) and B (balance);

(4) SA (strength and agility): RSA (running speed and agility) and S (strength).

The scores obtained in each subtest, in each motor area and in the total motor composite are converted into equivalent motor age and into descriptive category (classification) of motor performance.

\section{Data Analysis}

For statistical analysis, the SPSS (Statistical Package for Social Sciences) was employed, version 20.0. In this study, the Kruskal-Wallis test was applied, in order to verify possible differences in motor performance between the two groups when compared concomitantly; the Mann-Whitney test, adjusted by Bonferroni correction, to identify in which motor areas the groups differ from each other; the Likelihood Ratio Test, in order to evaluate possible differences in the classification of motor performance between the two groups, when compared concurrently; Test of Wilcoxon signed Stations, in order to verify possible differences between the values of the variable age and the values of other variables of interest. The level of statistical significance, signaled by an asterisk $(*)$, was $5 \%(0.050)$.

\section{Results}

In Table 1 the performance of the students for each of the motor areas was assessed. The Kruskal-Wallis test was applied and a statistically significant difference was noted between groups in the motor areas of fine manual control, manual coordination, strength and agility and total motor composite but not in body co-ordination.

Table 1

Distribution of Mean, SD (Standard Deviation) and P-Value for the Performance of GI and GII Students, in the Motor Areas of BOT-2

\begin{tabular}{lllll}
\hline Variables & Group & Mean & $S D$ & $p$-value \\
\hline \multirow{2}{*}{ FMC } & GI & 34.68 & 5.17 & $<0.001^{*}$ \\
& GII & 37.70 & 4.80 & $0.005^{*}$ \\
MC & GI & 33.47 & 5.80 & \\
& GII & 36.33 & 5.28 & 0.147 \\
BC & GI & 34.11 & 5.59 & $0.005^{*}$ \\
& GII & 35.67 & 6.36 & $<0.001^{*}$ \\
& GI & 39.68 & 6.27 & \\
& GII & 41.63 & 5.83 & 3.66 \\
\end{tabular}

Notes. FMC: fine manual control; CM: manual coordination; BC: body coordination; SA: strength and agility; TMC: total motor composite.

As shown in Table 1, statistically significant differences were observed in motor areas of fine manual control, manual coordination, strength and agility, and total motor composition; the Mann-Whitney test was applied and adjusted by Bonferroni correction, to identify which motor areas the groups differed from each 
other (see Table 2).

By the employment of the likelihood ratio test, it was possible to verify that there was a statistically significant difference between the groups, when compared in relation to performance classification in motor areas (see Table 3). The results showed that all groups in this study presented performance in motor areas below average.

Table 2

Distribution of P-Value, Referring to the Comparison of GI and GII in the Motor Areas of BOT-2

\begin{tabular}{ll}
\hline Variable & Pair of groups \\
\cline { 2 - 2 } & GI vs. GII \\
\hline FMC & $0.007^{*}$ \\
MC & 0.029 \\
SA & 0.273 \\
TMC & 0.010 \\
\hline
\end{tabular}

Notes. FMC: fine manual control; CM: manual coordination; SA: strength and agility; TMC: total motor composite.

Table 3

Frequency Distribution and Percentage Regarding to the Performance Classification of GI and GII in Motor Areas

\begin{tabular}{|c|c|c|c|c|c|c|}
\hline \multirow{2}{*}{ Variable } & \multirow{2}{*}{ Category } & \multicolumn{2}{|l|}{ GI } & \multicolumn{2}{|l|}{ GII } & \multirow{2}{*}{$p$-value } \\
\hline & & Freq. & Perc. (\%) & Freq. & Perc. (\%) & \\
\hline \multirow{5}{*}{ Class. FMC } & Well below average & 4 & 21.10 & 6 & 10.00 & \multirow{5}{*}{$0.043^{*}$} \\
\hline & Below average & 13 & 68.40 & 39 & 65.00 & \\
\hline & Average & 2 & 10.50 & 15 & 25.00 & \\
\hline & Above average & 0 & 0.00 & 0 & 0.00 & \\
\hline & Well above average & 0 & 0.00 & 0 & 0.00 & \\
\hline \multirow{5}{*}{ Class. MC } & Well below average & 6 & 31.60 & 1 & 1.70 & \multirow{5}{*}{$0.004^{*}$} \\
\hline & Below average & 12 & 63.20 & 50 & 83.30 & \\
\hline & Average & 1 & 5.30 & 9 & 15.00 & \\
\hline & Above average & 0 & 0.00 & 0 & 0.00 & \\
\hline & Well above average & 0 & 0.00 & 0 & 0.00 & \\
\hline \multirow{5}{*}{ Class. BC } & Well below average & 5 & 26.30 & 4 & 6.70 & \multirow{5}{*}{$0.025^{*}$} \\
\hline & Below average & 12 & 63.20 & 42 & 70.00 & \\
\hline & Average & 2 & 10.50 & 14 & 23.30 & \\
\hline & Above average & 0 & 0.00 & 0 & 0.00 & \\
\hline & Well above average & 0 & 0.00 & 0 & 0.00 & \\
\hline \multirow{5}{*}{ Class. SA } & Well below average & 1 & 5.30 & 0 & 0.00 & \multirow{5}{*}{$0.009^{*}$} \\
\hline & Below average & 8 & 42.10 & 26 & 43.30 & \\
\hline & Average & 10 & 52.60 & 34 & 56.70 & \\
\hline & Above average & 0 & 0.00 & 0 & 0.00 & \\
\hline & Well above average & 0 & 0.00 & 0 & 0.00 & \\
\hline \multirow{5}{*}{ Class. TMC } & Well below average & 3 & 15.80 & 4 & 6.70 & \multirow{5}{*}{$0.001^{*}$} \\
\hline & Below average & 15 & 78.90 & 46 & 76.70 & \\
\hline & Average & 1 & 5.30 & 10 & 16.70 & \\
\hline & Above average & 0 & 0.00 & 0 & 0.00 & \\
\hline & Well above average & 0 & 0.00 & 0 & 0.00 & \\
\hline
\end{tabular}

Notes. Class.: classification; FMC: fine manual control; CM: manual coordination; BC: body coordination; SA: strength and agility; TMC: total motor composite. 
Tables 4 and 5 show the comparison between chronological age and age equivalent for fine motor precision, fine motor integration, manual dexterity, upper-limb coordination, bilateral coordination, balance, running speed and agility and strength of the students in this study, after employing the Test of Wilcoxon signed Stations.

In Table 4, a statistically significant difference in the comparison between chronological age and other equivalent ages to GI scholars, in all motor subtests was noted.

Table 4

Comparison Between Chronological Age and Age Equivalent of GI

\begin{tabular}{clcll}
\hline & Age equivalent & Mean & $S D$ & $p$-value \\
\hline \multirow{4}{*}{ CA } & 10.82 & 0.89 & - \\
AE1 & 7.26 & 0.96 & $<0.001^{*}$ \\
GI & 7.27 & 2.22 & $<0.001^{*}$ \\
& AE2 & 6.81 & 1.83 & $<0.001^{*}$ \\
& AE3 & 8.17 & 1.45 & $<0.001^{*}$ \\
AE4 & 6.86 & 1.64 & $<0.001^{*}$ \\
& AE5 & 6.52 & 3.26 & $0.002^{*}$ \\
& AE6 & 6.81 & 1.63 & $<0.001^{*}$ \\
& AE7 & 7.83 & 2.57 & $0.001^{*}$ \\
\hline
\end{tabular}

Notes. AC: chronological age; AE1: age equivalent to fine motor precision; AE2: age equivalent to fine motor integration; AE3: age equivalent to manual dexterity; AE4: age equivalent to upper-limb coordination; AE5: age equivalent to bilateral coordination; AE6: age equivalent to balance; AE7: age equivalent to running speed and agility; AE8: age equivalent to strength.

In Table 5, a statistically significant difference in the comparison between chronological age and other equivalent ages to GII scholars in all motor subtests was noted.

Table 5

Comparison Between Chronological Age and Age Equivalent of GII

\begin{tabular}{cllll}
\hline & Age equivalent & Mean & $S D$ & $p$-value \\
\hline \multirow{4}{*}{ CA } & 10.24 & 1.05 & - \\
GII & 7.85 & 1.08 & $<0.001^{*}$ \\
& AE1 & 7.56 & 2.41 & $<0.001^{*}$ \\
& AE2 & 7.07 & 1.11 & $<0.001^{*}$ \\
& AE3 & 8.70 & 2.70 & $<0.001^{*}$ \\
& AE4 & 7.35 & 2.03 & $<0.001^{*}$ \\
& AE5 & 5.74 & 2.09 & $<0.001^{*}$ \\
& AE6 & 7.10 & 1.46 & $<0.001^{*}$ \\
& AE7 & 2.28 & $<0.001^{*}$ \\
\hline
\end{tabular}

Notes. AC: chronological age; AE1: age equivalent to fine motor precision; AE2: age equivalent to fine motor integration; AE3: age equivalent to manual dexterity; AE4: age equivalent to upper-limb coordination; AE5: age equivalent to bilateral coordination; AE6: age equivalent to balance; AE7: age equivalent to running speed and agility; AE8: age equivalent to strength.

\section{Discussion}

The results of this study showed that the motor performance of GII students was superior than the performance of GI students, in almost all motor areas assessed; which supports the literature (Rochelle \& Talcott, 2006; Rommelse et al., 2009; Capellini, Germano, \& Padula, 2010; Rosenblum, Aloni, \& Josman, 2010; Okuda \& Capellini, 2011). 
However, the motor area in which there was a higher statistically significant difference between GI and GII, was fine manual control, which involves fine motor integration and precision skills, motor components which are responsible for control and coordination of the distal muscles of the hands and fingers especially for grasping, drawing, cutting, and writing (R. H. Bruininks \& B. D. Bruininks, 2005; Okuda et al., 2011).

The difficulties with gross and fine motor skills, compared with the age equivalent students age is not routinely a part of developmental dyslexia framework, indicating that these students could have co-occurring DCD, because all participants had no other potential causes that could have affected their motor skills, such as Cerebral Palsy, for example (Kirby, 2008; Okuda \& Capellini, 2011).

In some of the literature (Nicolson \& Fawcett, 2011), it has been proposed that motor problems in students with dyslexia may be present, due to a deficit in automation, i.e., students with dyslexia have difficulty in automating the motor skills, so that, learning new motor skills is also impaired. Students with dyslexia have also been shown to have some difficulties with executive functions such as planning, organizing and executing motor action, which contributes to reaching low performance in global motor activities (Simos et al., 2011).

An important result also to be highlighted in this study is that motor performance, both for students with dyslexia and for students with good academic performance, was below average for their ages (see Tables 4 and 5). There appears to be a discrepancy with the comparison between chronological age and the stage of motor development in both cohorts. These findings may imply that the motor skills may not be taught or insufficiently practiced in the school or classroom and that teaching focusing on specific fine and gross motor coordination, ends up being neglected, and considered as a more technical and decontextualized motor activity (Okuda \& Capellini, 2011).

The data from this study showed that as both groups presented some motor difficulties this may also be attributed to the absence of motor experiences. However, it is hard to disentangle those with dyslexia having additional challenges with co-ordination and how much this was to do with lack of experience as well as an intrinsic additional difficulty with movement or planning.

It can contribute for obscuring the real cause of motor alterations found in this study, because in one hand we know, according to the description in the literature, that the relationship between alterations in motor coordination present in dyslexia can be a signal of increased vulnerability of neural work, which is responsible for sensorimotor integration of information (Goez \& Zelnik, 2008); on the other hand, it is still unknown the impact of lack of systematic work with fine and global motor skills since the beginning of literacy for students.

\section{Conclusion}

The students with dyslexia presented lower motor performance, when compared to students with good academic performance. However, both groups in this study showed performance below that expected for their age. It is difficult to be sure whether this is DCD or delay from lack of exposure and tracking children with some difficulties and if support was provided this then may be important to minimize long term difficulties.

These motor alterations can directly interfere in learning and acquisition of necessary skills for academic achievement, such as writing, for example, and in the early diagnosis and appropriate intervention in these cases.

Thus, the results of this study indicate the necessity for occupational therapists, speech therapists and educators to pay attention to early intervention for motor development in academic and clinical environment, to ensure the early identification and diagnosis of possible co-occurrences, such as DCD along with the presence of other learning problems, in order to guarantee better clinical and education assistance for this population. 
Finally, based on the findings of this study, it becomes necessary to carry out additional studies concerning this issue, both for the population with dyslexia and for the population without learning disabilities, in order to enable a better outline of the differences found, and the presence or absence of DCD in those students.

\section{References}

APA (American Psychiatric Association). (2013). Diagnostic and statistical manual of mental disorders (5th ed.). Arlington, V.A.: American Psychiatric Publishing.

Bruininks, R. H., \& Bruininks, B. D. (2005). Bruininks-Oseretsky Test of Motor Proficiency (Second Edition) (BOT-2). Minnesota: Pearson.

Capellini, S. A. (2009). Disturbio de aprendizagem versus dyslexia (Learning disorder versus dyslexia). In F. D. M. Fernandes, B. C. A. Mendes, \& A. L. P. Navas (Eds.), Tratado de fonoaudiologia (Treaty of speech language pathology and hearing) (2nd ed., pp. 352-361). São Paulo: Rocca. (in Portuguese)

Capellini, S. A., Germano, G. D., \& Padula, N. A. M. R. (2010). Dislexia e distúrbio de aprendizagem: Critérios diagnósticos (Dyslexia and learning disorder: Diagnostic criteria). In S. A. Capellini, G. D. Germano, \& V. L. O. Cunha (Eds.), Transtornos de aprendizagem e transtornos da atenção: da avaliação à intervenção (Learning disorders and attention disorder: from evaluation to intervention) (pp. 9-20). São José dos Campos: Pulso Editorial. (in Portuguese)

Corriveau, K. H., \& Goswami, U. (2009). Rhythmic motor entrainment in children with speech and language impairments: Tapping to the beat. Cortex, 45, 119-130.

Cruddace, S. A., \& Riddell, P. M. (2006). Attention processes in children with movement difficulties, reading difficulties or both. Journal of Abnormal Child Psychology, 34, 675-683.

Gabbard, C., \& Caçola, P. (2010). Los niños con trastorno del desarrollo de la coordinación tienen dificultad on la representación de las acciones (Children with developmental coordination disorder have difficulty with action representation). Revista de Neurológia, 50, 33-38. (in Spanish)

Goez, H., \& Zelnik, N. (2008). Handedness in patients with developmental coordination disorder. Journal of Child Neurology, 23, 151-154.

Gooch, D., Hulme, C., Nash, H. M., \& Snowling, M. J. (2013). Comorbidities in preschool children at family risk of dyslexia. Journal of Child Psychology and Psychiatry, 1-10. doi:10.1111/jcpp.12139.

Hedenius, M., Persson, J., Alm, P. A., Ullman, M. T., Howard Jr. J. H., Howard, D. V., \& Jennische, M. (2013). Impaired implicit sequence learning in children with developmental dyslexia. Research in Developmental Disabilities, 34, 3923-3935.

Kirby, A., Sugden, D., Beveridge, S., Edwards, L., \& Edwards, R. (2008). Dyslexia and developmental co-ordination disorder in further and higher education-Similarities and differences: Does the "label" influence the support given? Dyslexia, 14, 197-213.

Kirby, A. (2011). Transtorno do desenvolvimento da coordenação (tdc) e dyslexia (Developmental coordination disorder (DCD) and dyslexia). In L. M. Alves, R. Mousinho, \& S. A. Capellini, (Eds.), Dislexia: Novos temas, novas perspectivas (Dyslexia: New themes, new perspectives) (pp. 327-42). Rio de Janeiro: Wak Editora. (in Portuguese)

Lingam, R., Hunt, L., Golding, J., Jongmans, M., \& Emond, A. (2009). Prevalence of developmental coordination disorder using the DSM-IV at 7 years of age: A UK population-based study. Pediatrics, 123, 693-700.

Martin, N. C., Piek, J., Baynam, G., Levy, F., \& Hay, D. (2010). An examination of the relationship between movement problems and four common developmental disorders. Human Movement Science, 29, 799-808.

Nicolson, R. I., \& Fawcett, A. J. (2011). Dyslexia, dysgraphia, procedural learning and the cerebellum. Cortex, 47, 117-127.

Okuda, P. M. M., \& Capellini, S. A. (2011). Transtorno do desenvolvimento da coordenação em escolares com dislexia, transtornos e dificuldades de aprendizagem (Developmental coordination disorder of students with dyslexia, learning disorder and learning disabilities). In A. A. Ribeiro (Ed.), Temas em cognição, linguagem e aprendizagem (Themes in cognitions, language and learning) (pp. 153-165). Ubá, M.G.: Suprema Editora Ltda. (in Portuguese)

Okuda, P. M. M., Lourencetti, M. D., Santos, L. C. A., Padula, N. A. M. R., \& Capellini, S. A. (2011). Fine motor coordination of students with dyslexia and attention deficit disorder and hyperactivity. CEFAC Journal, 13, 876-885. (in Portuguese)

Pieters, S., De Block, K., Scheiris, J., Eyssen, M., Desoete, A., Deboutte, D. et al. (2012). How common are motor problems in children with a developmental disorder: Rule or exception? Child: Care, Health and Development, 38, 139-145. 
Rochelle, K. S. H., \& Talcott, J. B. (2006). Impaired balance in developmental dyslexia? A meta-analysis of the contending evidence. Journal of Child Psychology and Psychiatry, 47, 1159-1166.

Rommelse, N. N. J., Altink, M. E., Fliers, E. A., Martin, N. C., Buschgens, C. J. M., Hartman, C. A., et al. (2009). Problems in ADHD: Degree of association, shared endophenotypes, and formation of distinct subtypes: Implications for a future DSM. Journal of Abnormal Child Psychology, 37, 793-804.

Rosenblum, S., Aloni, T., \& Josman, N. (2010). Relationships between handwriting performance and organizational abilities among children with and without dysgraphia: A preliminary study. Research in Developmental Disabilities, 31, 502-509.

Simos, P. G., Rezaie, R., Fletcher, J. M., Juranek, J., Passaro, A. D., Li, Z.,... Papanicolaou, A. C. (2011). Functional disruption of the brain mechanism for reading: effects of comorbidity and task difficulty among children with developmental learning problems. Neuropsychology, 25, 520-534.

Stoodley, C. J., \& Stein, J. F. (2011). The cerebellum and dyslexia. Cortex, 47, 101-116.

Summers, J., Larkin, D., \& Dewey, D. (2008). Activities of daily living in children with developmental coordination disorder: Dressing, personal hygiene, and eating skills. Human Movement Science, 27, 215-29.

Valdois, S. (2010). Dyslexia (developmental). In G. Koob, M. Le Moal, \& R. Thompson (Eds.), Encyclopedia of behavioral neuroscience (pp. 454-460). Oxford: Academic Press.

Tsiotra, G. D., Nevill, A. M., Lane, A. M., \& Koutedakis, Y. (2009). Physical fitness and developmental coordination disorder in Greek children. Pediatric Exercise Science, 21, 186-195.

Willrich, A., Azevedo, C. C. F., \& Fernandes, J. O. (2009). Motor development in childhood: Influence of the risk factors and intervention programs. Journal of Neuroscience, 17, 51-56. (in Portuguese)

Zwicker, J. G., Missiuna, C., Harris, S. R., \& Boyd, L. A. (2011). Brain activation associated with motor skill practice in children with developmental coordination disorder: An fMRI study. International Journal of Developmental Neuroscience, 29, 145-152. 